\title{
Concluding Remarks: Righting Democratic Wrongs
}

\author{
Philippe Cayla and Catriona Seth
}

In the space of a couple of months in 2012, France has held four elections, two for the Presidency, two for the National Assembly. One of us voted on all four occasions. The other on none. We are both law-abiding, tax-paying citizens in full-time employment. We are both of voting age. The difference is that one of us is a Frenchman living in France and that the other lives and works in France, thanks to free circulation which is at the heart of the European union, but holds British nationality and can therefore not vote in the country in which she resides, works and pays taxes. It is in order both to foster a true spirit of European nationhood and to correct such lacunae that we launched our 'Let me vote' ECI and the EUDO forum debate. Though neither of us is competent to comment on the finer points of EU and constitutional law, we have both been impressed by the wide-ranging and challenging proposals and demonstrations set out by the different participants and would like to express our deep gratitude to those who have taken the time to make their feelings and ideas known, whether they ultimately come out totally or partially in favour of or against our initiative. We can only agree with Dora Kostakopoulou's opening remarks, when she notes that the different contributions to the forum 'have provided a number of valuable reflections on matters of principle, policy, strategy, and tactics in the light of contemporary political developments at both European Union and domestic levels.' She adds: 'By clarifying matters of principle as well as issues of politics, they have outlined several trajectories and shed ample light onto the pros and cons of the European Citizens' Initiative.' The variety and depth of the comments tend to confirm that, as Jo Shaw states, the ECI is a timely initiative on an important question.

We would like to start by stressing a point which the eminent specialists who have expressed their ideas have perhaps not always taken fully into account, i.e. the limits which the very procedure of ECIs imposes. Our ECI's object has been analysed, but not its starting point: a valiant but fragile citizens' committee. We are neither an institution within the Union, nor a political party, a trades-union or even a powerful lobby. We are a small group of well-meaning citizens, strong believers in the European cause, but with no means other than those afforded by the ECI's procedure. The procedure 
itself is very restrictive: it only allows us to make suggestions which can lead the European Commission to propose legislative measures within the framework of existing treaties. There is no possibility therefore for us to encourage actions in the field of nationality, for instance, or with regard to the rights attributed to third-country nationals, as some contributors like Ángel Rodríguez seem to suggest. We feel strongly that such questions are outside our scope. In addition, it must be noted that the requirement of collecting a million signatures within a year is a very tough one and that the only chance of meeting it is for an ECI to have a simple, clear and ambitious object.

Our contention is that there is a case to be made for Europeans to be granted a form of super-citizenship, in the tradition of the civis romanus who was a citizen of Rome without losing his own statehood. We believe that at a time when Europe is increasingly seen as a bureaucratic and costly system with no positive impact on everyday life, a form of European citizenship which would allow one to vote in all elections of one's country of residence when within the EU, could only enhance our feelings towards the Union and serve to foster increased implication in its development. It would be a concrete way of recognising that we share a common culture and that our future lies in a common destiny. David Bellamy can reassure those who see mobile EU citizens as benefits tourists. On the whole, those who are interested in an initiative such as our ECI are quite the opposite: dedicated professionals, open to European cultures and languages, conscious of a shared heritage, desirous to contribute to a peaceful and prosperous future for the EU.

\section{What are our ECI's fundamental objectives? There are three of them:}

1) To give European citizenship its full meaning by making it grant access to all fundamental rights, including the right to vote, whatever one's country of residence. It is a principle of equality for Europeans.

Dimitry Kochenov makes a very useful point with his question: 'Who is a foreigner?' Surely an EU national within the EU, whether in his or her home state or elsewhere, is not a foreigner and must not be treated as such. Dora Kostakopoulou adds that it is unsustainable in a democracy to ask people to contribute fully but only to treat them as de facto second-class citizens.

\section{2) To give mobility (i.e. the principle of free movement within Europe) its full scope.}

There is general agreement amongst the authors that the current situation entails a serious democratic deficit and that it is absurd that this should 
derive from the exercise of one of the EU's core rights: free movement. As David Owen points out: 'This is a democratic wrong since it is not democratically legitimate that a person lawfully exercising a civil right shall in virtue of such exercise be deprived of a political right.' Is this dysfunction of democracy, as Rainer Bauböck suggests, only the case for those who, like Britons or Danes, do not keep home voting rights permanently wherever they live? Is it not, rather, the case for anyone who is integrated in their country of residence in every respect (working, speaking the language, paying tax etc.) but deprived of the democratic rights granted to those who were born there (or whose parents were born there), but who may, in the most extreme of cases, never go there. When you move from Perpignan to Calais or from Aberdeen to Exeter, you vote for the mayor of the town in which you live. You do not forever cast your vote in the ward in which you were born. In the same way, would it not be logical to consider that you take your voting rights with you when you move overseas but stay within the EU? In a true European Union, living in Vienna or in Seville should be of no more consequence than moving from Genoa to Milan: you should not be disenfranchised because you have chosen to exercise your right to mobility Roxana Barbulescu's analogy with the portability of pensions or medical insurance across national borders within the European Union is a demonstration of the fact that rights acquired in one EU State can be enjoyed in another. As a matter of consequence, we do not believe that simply ensuring that all EU citizens maintain a permanent right to vote in their home nations is the appropriate solution: we are most directly affected by what happens in the land in which we live and work - if income tax is to increase in Greece, this is less likely to have instant consequences on the everyday existence of Greeks living and working in Brussels, than if it goes up in Belgium. Martin Wilhelm's vote exchange system implicitly recognises that citizens can feel more immediately concerned by the political situation of the state in which they reside than by elections in their home country.

\section{3) Finally, to give the democratic principle, 'No taxation without repre- sentation' its full meaning. This is a consequence of applying the principle of solidarity to all residents.}

This principle, which launched the American Revolution, is already recognised locally, as Kees Groenendijk stresses. It must be extended at regional and national levels too: Europeans resident in the EU pay income tax as well as local taxes. Currently, we are being taxed and some of us, like the pigs in Animal Farm, are more equal than others. Even the Commission has to agree that this is the case, as Andrew Duff's recent exchange about the European Convention on Human Rights shows. 
In this context, let us take another look at some of the objections set out by certain contributors.

1) The main objection is that a European citizen who resides in another member state must take out its nationality if $s /$ he wants to vote there.

Answer: clearly, if the principle of free circulation is to apply, any European has to be able to move to another EU country whenever s/he wants to - why not every year if the labour market makes this desirable? One can recall here that Olivier Blanchard, the IMF Chief Economist had imagined in 1998 that the Euro zone could fail because of lack of fluidity in the European labour market. Asking EU nationals to acquire another EU nationality in order to be able to vote does not seem to offer an apposite answer: in these changing times, many of us will live and study in several EU states within our lifetime - Sue Collard helpfully gives a couple of examples of people concerned by such moves. Does this mean that each time we take up residence in a country we should pick up the nationality, thanks to simplified procedures? Or would this not debase the concept, were we to end up, routinely, with three, four or five passports? As Rainer Bauböck suggests, citizenship should be seen as a lifelong status. Unlike him we feel that, as a result, one EU passport should be enough for anyone: citizenship of any EU nation should make one an EU citizen, wherever one lives. This is not to preclude anyone from holding a second EU citizenship or to deny anyone dual nationality. Acquiring a country's passport should not, however, be a prerequisite in order to vote in its national elections if one is already an EU citizen within the Union. As Alain Brun puts it in a nutshell: 'I understand European citizenship as the right to be considered as a national by any member state other than the one whose nationality I hold, as soon as I am in relation with its authorities, in one way or another.' Or, to echo Dimitry Kochenov's words: 'Since member state nationalities are in the absolute majority of cases legally inconsequential for EU citizens travelling around the EU, connecting democratic participation with naturalisation amounts to artificially inflating the importance of an abolished status.' In addition, Roxana Barbulescu makes a very interesting comment when she opposes the individual solution of naturalisation and the collective process of enfranchisement of EU citizens.

Obviously, no one is going to change nationalities every year. In addition, on a legal level, questions of nationality are outside an ECI's scope.

2) Second objection: it is more urgent to improve the current situation, viz access to and participation in municipal and European elections, and prudent to limit the demand for new rights for Europeans to regional elections. 
Answer: be that as it may, such a proposal would never be attractive enough to collect a million signatures. We fail, in addition, to see the legitimacy of giving limited voting rights to EU citizens. Why should it be all right for them to elect their mayor, but not the member of a legislative assembly or a president? A collateral advantage of our ECI is that granting EU citizens full voting rights in their host country would probably increase general awareness of - and interest in - European elections. This would in turn almost certainly boost the turnout and the visibility of such polls. A bold and supranational step, such as the one we propose, would also give Europe a more definite structure, de facto, rather than leaving it stuck in a halfway house between a confederation and an association.

3) Further amendment: conditions of residence and the question of whether one could potentially vote in two countries need to be envisaged.

Obviously such issues will have to be dealt with, but they are not within our remit.

4) Last objection: dealing with third-country nationals is paramount.

Should they acquire EU citizenship, third-country nationals would of course benefit from our ECI, but their rights are outside its scope.

There are clearly political, philosophical and legal aspects to take into account - there would also be economic consequences to any change in the status quo. Debates about EU citizenship are, more than ever, debates about the future of Europe itself - and thus carry huge symbolic value too. Hannes Swoboda rightly affirms that 'the necessary evolution of EU citizenship leads to a gradually growing relevance of residence as [the] defining criterion for the exercise of related rights.' As in clothes shops where 'one size fits all' generally means nothing will be a perfect fit for anyone, our ECI falls short of some people's ideal scenario. The five options David Owen sets out offer unequal advantages, though he stresses that the ECI ticks a number of boxes. Obviously we are aware that obtaining and implementing voting rights for EU nationals in their country of residence (or allowing them to choose between voting in their home country and their state of residence) will be an uphill struggle. However, Tony Venables hits the nail on the head when he states that "the right to vote is so fundamental to democracy that any arguments reflecting the difficulties of putting it into effect pale into insignificance'.

The different cases made for and against our ECI in the EUDO forum debate have but strengthened our resolve. There is broad consensus that the current situation is untenable. The idea that our proposal is 'timely' is men- 
tioned several times and we can only see this as an encouragement, along with the fact that most contributors affirm that they will sign it. We are grateful to them for this. We believe, more than ever, that our case is a strong one. The fact that our ECI has been officially validated shows that our proposal does not fall outside the Commission's scope. Next year (2013) is the European year of citizens. Let us do all we can, together, to right democratic wrongs and endow European citizens with full voting rights wherever they choose to reside within the EU.

Open Access This chapter is licensed under the terms of the Creative Commons Attribution 4.0 International License (http://creativecommons.org/licenses/by/4.0/), which permits use, sharing, adaptation, distribution and reproduction in any medium or format, as long as you give appropriate credit to the original author(s) and the source, provide a link to the Creative Commons license and indicate if changes were made.

The images or other third party material in this chapter are included in the chapter's Creative Commons license, unless indicated otherwise in a credit line to the material. If material is not included in the chapter's Creative Commons license and your intended use is not permitted by statutory regulation or exceeds the permitted use, you will need to obtain permission directly from the copyright holder.

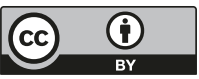

